\title{
Anthropometry and body composition of vertically HIV-infected children and adolescents under therapy with and without protease inhibitors
}

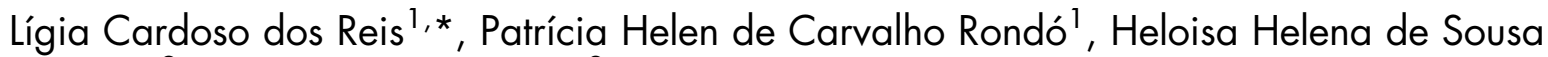 \\ Marques $^{2}$ and Neuber José Segri ${ }^{3}$ \\ 'Department of Nutrition, School of Public Health, University of São Paulo, Avenida Dr Arnaldo 715, São Paulo, SP, \\ CEP 01246-904, Brazil: ${ }^{2}$ Institute of Child Health, School of Medicine, University of São Paulo, São Paulo, SP, \\ Brazil: ${ }^{3}$ Department of Statistics, Federal University of Mato Grosso, Cuiabá, MT, Brazil
}

Submitted 14 October 2013: Final revision received 20 February 2014: Accepted 30 June 2014: First published online 13 August 2014

\begin{abstract}
Objective: Although the benefits of highly active antiretroviral therapy (HAART) have been documented, it is thought to be associated to disturbances in nutritional status. These disturbances may occur early in life and are poorly understood. The present study aimed to investigate the relationship between anthropometric parameters and body composition of perinatally HIV-infected children and adolescents under HAART, according to use and non-use of protease inhibitors. Design: Cross-sectional study undertaken between August and December 2007. Demographic, socio-economic, clinical and anthropometric data were collected from the patients. The $\chi^{2}$ test, Wilcoxon rank sum test (Mann-Whitney) and $t$ test were used to compare the following variables between users and non-users of protease inhibitors: age, gender, per capita income, HAART exposure, antiretroviral therapy adopted in the last three years, CD4 count, viral load, pubertal stage, nutritional status (BMI-for-age, height-for-age, waist and neck circumferences, triceps skinfold thickness, body fat percentage, upper-arm fat area and upper-arm muscle area).

Setting: An HIV/AIDS out-patient clinic, São Paulo, Brazil.

Subjects: One hundred and fifteen patients (children and adolescents aged 6-19 years).

Results: Protease inhibitors users had a higher prevalence of stunting $(P=0.03)$, lower BMI $(P=0.03)$ and lower percentage of body fat $(P=0.05)$ compared with non-users. There was no statistically significant difference between the HAART regimens and measurements of fat adiposity.

Conclusions: The findings of the study suggest that children and adolescents under protease inhibitors are at higher risk of growth and development deviations, but not at risk of body fat redistribution.
\end{abstract}

Keywords
HIV
Nutrition
Children
Highly active antiretroviral therapy
According to the Joint UN Programme on HIV/AIDS ${ }^{(1)}$, 35.3 million people were living with HIV/AIDS at the end of 2012 and 260000 children became newly infected in 2012 .

Morbidity and mortality associated with HIV infection have been reduced dramatically in the paediatric population with the introduction of highly active antiretroviral therapy (HAART) into routine clinical use ${ }^{(2-4)}$. Although beneficial to the prognosis of HIV infection, exposure to HAART has been associated with disturbances in the nutritional status of this population group ${ }^{(5-9)}$, including body fat distribution abnormalities, which may represent an increased risk for premature CVD ${ }^{(5,8)}$. HAART also does not seem to fully reverse the effects of HIV/AIDS on children's growth ${ }^{(10)}$. In Brazil, the free and universal access to HAART is relatively recent $^{(11)}$, so there are very few studies discussing the side-effects of HAART in the paediatric population ${ }^{(12)}$. Furthermore, associations between antiretroviral therapy and anthropometric disturbances in children and adolescents are poorly understood. Thus, the present study aimed to investigate the relationship between anthropometric parameters and body composition of perinatally HIVinfected children and adolescents under HAART, according to use and non-use of protease inhibitors. 


\section{Experimental methods}

The present cross-sectional study involved 115 children and adolescents, aged 6-19 years, who acquired HIV infection perinatally and were under HAART. All participants were regularly followed at the Institute of Child Health, University of São Paulo, Brazil, one of the three largest reference centres for treatment of paediatric patients with HIV/AIDS in São Paulo city. The HIV/AIDS out-patient clinic of the Institute of Child Health receives patients not only from São Paulo, but also from other cities of the country. Thus, the sample can be considered representative of Brazilian children and adolescents living with HIV/AIDS.

Demographic, socio-economic, clinical and anthropometric data were obtained by a questionnaire, physical examination and medical records after the caregivers signed informed consent, between August and December 2007.

The recall period for medical history was limited to the past three years to ensure that the patients had access to the medicines that make up HAART.

CD4 values were characterized according to the WHO guidelines for the paediatric population ${ }^{(13)}$ : no immunological suppression $\left(\geq 500\right.$ cells $\left./ \mathrm{mm}^{3}\right)$, slight suppression (350-499 cells $\left./ \mathrm{mm}^{3}\right)$ and moderate/severe suppression $\left(\leq 349\right.$ cells $\left./ \mathrm{mm}^{3}\right)$. Detectable viral load indicated the presence of HIV replication.

The patients were grouped according to the $\mathrm{WHO}^{(14)}$ definition for childhood ( $<10$ years of age) and adolescence (10-19 years of age). Pubertal stage was self-assessed with drawings that showed the different Tanner stages for secondary sex characteristics ${ }^{(15)}$.

The anthropometric assessment comprised determinations of weight, height, waist and neck circumferences, and triceps skinfold thickness. The measurements were taken in triplicate according to the standardized procedures of Frisancho ${ }^{(16)}$ and Lohman et al. ${ }^{(17)}$. Weight was measured using a portable electronic scale (Sohnle ${ }^{\circledR}$, model 7500, Murrhardt, Germany), accurate to $100 \mathrm{~g}$. Height was measured with a Leicester stadiometer $\left(\right.$ SECA $^{\circledR}$ portable height measure model, Hamburg, Germany), accurate to $1 \mathrm{~mm}$. BMI $\left(\mathrm{kg} / \mathrm{m}^{2}\right)$ was determined as weight divided by the square of the height. $Z$-scores were calculated for BMI-for-age and height-for-age using the WHO Anthro ${ }^{(18)}$ software. $\mathrm{WHO}^{(19)}$ cut-off points were used to categorize BMI into underweight, normal weight, overweight or obesity, and height into low or normal height. The mid-arm, waist and neck circumferences were obtained with an inextensible centimetre-graded measuring tape (Stanley ${ }^{\circledR}$, model 34103, New Britain, CT, USA), accurate to $1 \mathrm{~mm}$. Triceps skinfold thickness was taken with a calibrated Lange ${ }^{\circledR}$ adipometer (Beta-Technology, Santa Cruz, CA, USA) on the right side of the body; accurate to $1 \mathrm{~mm}$. Triceps skinfold thickness was categorized into percentiles according to Frisancho ${ }^{(20)}$.

The mid-arm fat and muscle areas were calculated using the equations recommended by Frisancho ${ }^{(20)}$. The sex- and age-specific percentiles recommended by the Centers for Disease Control and Prevention ${ }^{(21)}$ were applied to categorize waist circumference and a percentile $>75$ th was used to identify abdominal obesity as proposed by Savva et $a{ }^{(22)}$. Neck circumference was assessed at the level of the thyroid cartilage and classified according to age- and sex-specific cut-off values recommended by Nafiu et al. ${ }^{(23)}$.

Body fat percentage was obtained by bioelectrical impedance analysis using the Biodynamics ${ }^{\circledR}$ analyser (model 310, Seattle, WA, USA). The patient was positioned in horizontal decubitus with ornaments removed. Data on the patient's age, gender, weight and height were entered into the analyser. Surface gel electrodes were dorsally placed on the right side of the body, according to the manufacturer's instructions, at the wrist, hand, ankle and foot, after each site was cleaned with alcohol. The patient was instructed to slightly abduct his or her arms and legs.

The variables included in the analysis were: age, gender, per capita income, HAART exposure, antiretroviral therapy adopted in the last three years, CD4 count, viral load, pubertal stage, nutritional status (BMI-for-age, heightfor-age, waist and neck circumferences, triceps skinfold thickness, body fat percentage, upper-arm fat area and upper-arm muscle area).

In order to evaluate the relationship among the variables investigated and the antiretroviral therapy adopted for the patients, the regimens were separated into protease inhibitor (PI)-containing and non PI-containing therapy.

Mean, median, standard deviation, minimum and maximum values were calculated to describe all the variables investigated. A $t$ test was used to compare means of variables with normal distribution, according to variables with only two categories, and a non-parametric Wilcoxon (Mann-Whitney) compared the means of variables with non-normal distribution.

Correlations were assessed by the Spearman nonparametric test and associations were investigated by Pearson's $\chi^{2}$ test. The statistical significance was set at $P<0.05$. The statistical analysis was conducted with the Stata 9 statistical software package.

The study was conducted according to the guidelines laid down in the Declaration of Helsinki and all procedures involving human subjects were approved by the Ethical Committees of the School of Public Health and Institute of Child Health/School of Medicine, University of São Paulo, SP, Brazil. Written informed consent was obtained from all participants.

\section{Results}

At the time of enrolment, 120 children and adolescents seen in the HIV/AIDS out-patient clinic of the Institute of Child Health, São Paulo, were eligible. One patient refused to participate and four patients had not used any medication over the last three years. Therefore, the final sample 
Table 1 Characteristics of the vertically HIV-infected children and adolescents under HAART (n 115), São Paulo, Brazil, AugustDecember 2007

\begin{tabular}{|c|c|c|c|c|}
\hline Characteristic & $n$ & $\%$ & Mean & SD \\
\hline Age (years) & & & $11 \cdot 8$ & $2 \cdot 9$ \\
\hline $6-9$ & 26 & $22 \cdot 6$ & & \\
\hline $10-19$ & 89 & $77 \cdot 4$ & & \\
\hline \multicolumn{5}{|l|}{ Gender } \\
\hline Male & 55 & 47.8 & & \\
\hline Female & 60 & $52 \cdot 2$ & & \\
\hline \multicolumn{3}{|l|}{ Per capita income (Brazilian minimum wage ${ }^{\star}$ ) } & $1 \cdot 2$ & 1.5 \\
\hline$<1$ & 74 & $64 \cdot 4$ & & \\
\hline$\geq 1$ & 41 & $35 \cdot 6$ & & \\
\hline \multicolumn{5}{|l|}{ Pubertal stage $\dagger$} \\
\hline Initial (Tanner I and II) & 67 & $58 \cdot 8$ & & \\
\hline Intermediate/advanced (Tanner III, IV and V) & 47 & $41 \cdot 2$ & & \\
\hline \multicolumn{5}{|l|}{ Antiretroviral therapy adopted } \\
\hline PI users & 64 & $55 \cdot 7$ & & \\
\hline PI non-users & 51 & $44 \cdot 3$ & & \\
\hline \multicolumn{3}{|l|}{ Degree of immunodeficiency $\left(\mathrm{CD} 4\right.$ cells $\left./ \mathrm{mm}^{3}\right) \ddagger$} & $571 \cdot 3$ & 355.5 \\
\hline Without suppression $(\geq 500)$ & 55 & $47 \cdot 8$ & & \\
\hline Slight suppression $(\geq 350$ and $<500)$ & 28 & $24 \cdot 4$ & & \\
\hline Moderate/severe suppression $(<350)$ & 32 & $27 \cdot 8$ & & \\
\hline Viral load (copies/mm³) & & & 26207.9 & $65107 \cdot 6$ \\
\hline \multicolumn{3}{|l|}{ BMI-for-age $(Z$-score $) \S$} & -0.072 & 1.015 \\
\hline Underweight & 4 & 3.5 & & \\
\hline Normal weight & 93 & $80 \cdot 9$ & & \\
\hline Overweight & 18 & $15 \cdot 6$ & & \\
\hline \multicolumn{3}{|l|}{ Height-for-age (Z-score)§ } & -1.006 & $1 \cdot 194$ \\
\hline Normal & 91 & $79 \cdot 1$ & & \\
\hline Low & 24 & $20 \cdot 9$ & & \\
\hline \multicolumn{5}{|l|}{ Waist circumference-for-age (percentile)\| } \\
\hline Normal & 112 & 97.4 & & \\
\hline Obesity & 3 & 2.6 & & \\
\hline \multicolumn{5}{|l|}{ Neck circumference-for-age (percentile)ף } \\
\hline Low risk of overweight & 109 & 94.8 & & \\
\hline High risk of overweight & 6 & $5 \cdot 2$ & & \\
\hline \multicolumn{5}{|l|}{ Triceps skinfold thickness (percentile) ${ }^{\star *}$} \\
\hline$<5$ (depletion of adipose tissue) & 39 & 33.9 & & \\
\hline$\geq 5$ and $<95$ (normal) & 76 & $66 \cdot 1$ & & \\
\hline$\geq 95$ (obesity) & 0 & 0.0 & & \\
\hline \multicolumn{5}{|c|}{ 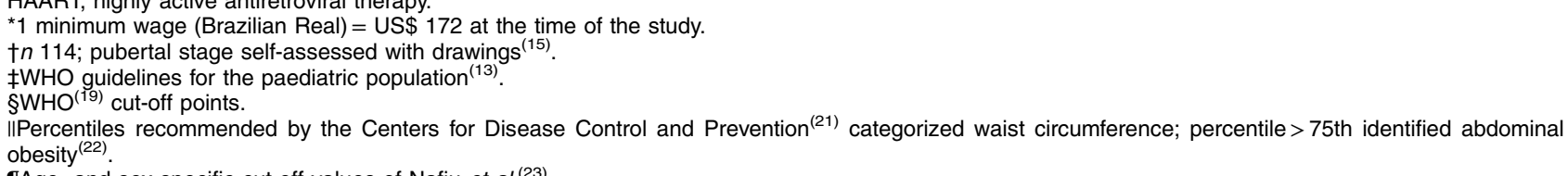 } \\
\hline
\end{tabular}

consisted of 115 children and adolescents from 6 to 19 years of age who were vertically HIV-infected.

The demographic, socio-economic, clinical and nutritional characteristics of the patients are summarized in Table 1. The majority of the individuals were adolescents, female, from low-income background and in early pubertal stages. Most of the patients were taking PI, almost half ( $47.8 \%$ ) had CD $4 \geq 500$ cells $/ \mathrm{mm}^{3}$ and their mean viral load (copies $/ \mathrm{mm}^{3}$ ) was 26207.9 . Approximately four-fifths (80.9\%) presented a normal weight (BMI-for-age $Z$-score $\geq-2 \cdot 0$ and $<+1 \cdot 0$ ), $15 \cdot 6 \%$ were overweight (BMI-for-age $Z$-score $\geq+1 \cdot 0$ ) and $3.5 \%$ underweight (BMI-for-age $Z$-score $<-2 \cdot 0)$. A high prevalence $(20.9 \%)$ of stunting (height-for-age $Z$-score $<-2 \cdot 0$ ) and low prevalences of central adiposity, assessed by waist (2.6\%) and neck circumferences $(5 \cdot 2 \%)$, were seen in this population. Depletion in adipose tissue (percentile $<5$ th) was identified in $33.9 \%$ children and adolescents according to the triceps skinfold thickness in percentiles.

Table 2 compares the nutritional and clinical characteristics of the children and adolescents vertically HIVinfected under HAART, according to PI use. The results show that PI users had higher prevalence of stunting $(P=0.03)$, lower BMI $(P=0.03)$ and lower percentage of body fat $(P=0.05)$ compared with PI non-users. There were no differences for the other variables investigated: age, gender, HAART exposure, CD 4 count, viral load, pubertal stage, waist and neck circumferences, triceps skinfold thickness, upper-arm fat area and upper-arm muscle area. 
Table 2 Nutritional and clinical characteristics of the vertically HIV-infected children and adolescents under HAART, according to pattern of PI use (n 115), São Paulo, Brazil, August-December 2007

\begin{tabular}{|c|c|c|c|c|c|c|c|c|c|}
\hline \multirow[b]{2}{*}{ Characteristic } & \multicolumn{4}{|c|}{ PI users ( $n$ 64) } & \multicolumn{4}{|c|}{ PI non-users ( $n$ 51) } & \multirow[b]{2}{*}{$P$} \\
\hline & $n$ & $\%$ & Mean & SD & $n$ & $\%$ & Mean & SD & \\
\hline Age group* & & & 11.75 & 2.94 & & & 11.88 & $2 \cdot 89$ & $0.81^{\star *}$ \\
\hline Children & 17 & $26 \cdot 6$ & & & 9 & $17 \cdot 6$ & & & \\
\hline Adolescents & 47 & 73.4 & & & 42 & 82.4 & & & $0.26 \dagger \dagger$ \\
\hline Gender & & & & & & & & & $0.60+\dagger$ \\
\hline Male & 32 & $50 \cdot 0$ & & & 23 & $45 \cdot 1$ & & & \\
\hline Female & 32 & $50 \cdot 0$ & & & 28 & 54.9 & & & \\
\hline HAART exposure (months) & & & $109 \cdot 9$ & $28 \cdot 8$ & & & $99 \cdot 7$ & $41 \cdot 7$ & $0.12 \ddagger \ddagger$ \\
\hline CD4 (cells $/ \mathrm{mm}^{3}$ ) & & & 569.3 & 387.7 & & & $556 \cdot 4$ & 308.2 & $0.85 \ddagger \ddagger$ \\
\hline Viral load (copies $/ \mathrm{mm}^{3}$ ) & & & $37529 \cdot 0$ & $84945 \cdot 8$ & & & $12001 \cdot 0$ & 14251.4 & $0.88 \ddagger \ddagger$ \\
\hline Pubertal stage† & & & & & & & & & $0.70+\dagger$ \\
\hline Initial (Tanner I and II) & 36 & $57 \cdot 1$ & & & 31 & $60 \cdot 8$ & & & \\
\hline Intermediate/advanced (Tanner III, IV and V) & 27 & 42.9 & & & 20 & $39 \cdot 2$ & & & \\
\hline BMI-for-age (Z-score) $\ddagger$ & & & -0.224 & 1.046 & & & 0.118 & 0.953 & $0.07^{* *}$ \\
\hline Underweight & 3 & 4.7 & & & 1 & $2 \cdot 0$ & & & $0.45 \dagger \dagger$ \\
\hline Normal weight & 53 & $82 \cdot 8$ & & & 40 & 78.4 & & & \\
\hline Overweight & 8 & 12.5 & & & 10 & $19 \cdot 6$ & & & \\
\hline BMI $\left(\mathrm{kg} / \mathrm{m}^{2}\right)$ & & & $17 \cdot 8$ & $2 \cdot 7$ & & & $18 \cdot 8$ & $2 \cdot 8$ & $0.03 \neq \ddagger$ \\
\hline Height-for-age (Z-score) $\ddagger$ & & & -1.227 & $1 \cdot 103$ & & & -0.730 & 1.257 & $0.03^{\star *}$ \\
\hline Normal & 46 & 71.9 & & & 45 & 88.2 & & & $0.03+t$ \\
\hline Stunted & 18 & $28 \cdot 1$ & & & 6 & 11.8 & & & \\
\hline Waist circumference-for-age (percentile)§ & & & & & & & & & $0.43+\dagger$ \\
\hline Normal & 63 & 98.4 & & & 49 & $96 \cdot 1$ & & & \\
\hline Obesity & 1 & 1.6 & & & 2 & 3.9 & & & \\
\hline Waist circumference $(\mathrm{cm})$ & & & 64.9 & $7 \cdot 3$ & & & 67.4 & 8.4 & 0.09 抹 \\
\hline Neck circumference-for-age (percentile)\| & & & & & & & & & $0.77 \dagger \dagger$ \\
\hline Low risk of overweight & 61 & $95 \cdot 3$ & & & 48 & $94 \cdot 1$ & & & \\
\hline High risk of overweight & 3 & 4.7 & & & 3 & 5.9 & & & \\
\hline Neck circumference $(\mathrm{cm})$ & & & 29.0 & 2.4 & & & $29 \cdot 3$ & $3 \cdot 2$ & $0.80 \ddagger \ddagger$ \\
\hline Triceps skinfold thickness (percentile) & & & & & & & & & $0.09+t$ \\
\hline$<5$ (depletion of adipose tissue) & 26 & $40 \cdot 6$ & & & 13 & 25.5 & & & \\
\hline$\geq 5$ and $<95$ (normal) & 38 & 59.4 & & & 38 & 74.5 & & & \\
\hline$\geq 95$ (obesity) & 0 & 0.0 & & & 0 & 0.0 & & & \\
\hline Triceps skinfold thickness (mm) & & & $9 \cdot 3$ & $4 \cdot 4$ & & & $10 \cdot 3$ & $4 \cdot 8$ & $0.22 \ddagger \ddagger$ \\
\hline Upper-arm fat area $\left(\mathrm{mm}^{2}\right)$ & & & $919 \cdot 0$ & $520 \cdot 5$ & & & 1074.5 & 605.5 & $0.11 \neq \ddagger$ \\
\hline Upper-arm muscle area $\left(\mathrm{mm}^{2}\right)$ & & & $2548 \cdot 0$ & 674.2 & & & $2780 \cdot 2$ & $781 \cdot 8$ & $0.08 \ddagger \ddagger$ \\
\hline Body fat $(\%)$ & & & 18.5 & 6.0 & & & $20 \cdot 6$ & 5.6 & $0.05^{\star \star}$ \\
\hline
\end{tabular}

HAART, highly active antiretroviral therapy; PI, protease inhibitors.

*WHO definition of childhood and adolescence ${ }^{(14)}$.

†Pubertal stage self-assessed with drawings ${ }^{(15)}$.

$\ddagger \mathrm{WHO}^{(19)}$ cut-off points.

§Percentiles recommended by the Centers for Disease Control and Prevention ${ }^{(21)}$ categorized waist circumference; percentile $>75$ th identified abdominal obesity $^{(22)}$.

IIAge- and sex-specific cut-off values of Nafiu et al. ${ }^{(23)}$.

ๆCategorized into percentiles according to Frisancho ${ }^{(20)}$.

${ }^{\star *}$ From $t$ test.

††From $x^{2}$ text.

¥†From Wilcoxon rank sum test (Mann-Whitney).

\section{Discussion}

The patients included in the present study comprise a representative sample of the Brazilian HIV-infected paediatric population with long exposure to HAART. A high prevalence of stunting (20.9\%) was seen among those individuals, especially in PI users.

The latest Household Budget Survey, undertaken by the Brazilian Institute of Geography and Statistics ${ }^{(24)}$, showed that $6.8 \%$ of children between 5 and 9 years of age were stunted and that the prevalence of this growth deviation decreased with age. Stunting has been observed in HIV-infected children ${ }^{(5,25-28)}$ and HAART is normally thought to improve growth ${ }^{(27)}$. However, HAART seems less effective in those under 1 year of age because of their poor clinical condition as they fulfilled the inclusion criteria for this therapy at a very young age, which suggests a more advanced disease ${ }^{(6)}$. The mechanism by which HIV replication affects growth has not been totally elucidated, but suppression of HIV, through antiretroviral therapy, is thought to have a favourable effect on growth ${ }^{(25)}$.

The eligible children and adolescents of the present study received HAART regimens for prolonged periods. Thus, their clinical condition associated with the use of lifelong different antiretrovirals may have negatively influenced growth patterns. 
Buonora et al. ${ }^{(29)}$ assessed the impact of HIV infection on the growth parameters of vertically infected adolescents and demonstrated that, even on HAART, they tended to have lower growth parameters throughout childhood and adolescence compared with the healthy population. Chhagan $e t a l .{ }^{(27)}$ found that stunted children on HAART displayed inappropriate catch-up. These findings highlight the importance of adequate growth velocity assessment of these patients even after antiretroviral therapy is introduced.

Similar to our finding, Tremeschin et al. ${ }^{(9)}$ referred that PI users presented lower mean BMI compared with PI non-users. Banerjee et $a l .^{(6)}$ found that children under HAART had a significantly lower mean BMI $Z$-score compared with the no-HAART group. Weight and height are highly correlated and may be affected by the HIV infection itself, social factors, as well as medical therapy. It is well established that a poor trend of anthropometric measurements is likely to increase the risk of mortality of these children $^{(28)}$. Chhagan et al. ${ }^{(27)}$ noticed that children under HAART who eventually died presented no improvements in anthropometry over time.

There is currently conflicting literature on whether lower mean or median BMI may represent the presence or absence of body fat redistribution. Aldrovandi et al. ${ }^{(30)}$ attributed the lower BMI in the HIV-infected group to differences in fat, primarily in the extremities. Alam et al. ${ }^{(31)}$ observed that median BMI differed according to presence $\left(19.4 \mathrm{~kg} / \mathrm{m}^{2}\right)$ or absence $\left(17.8 \mathrm{~kg} / \mathrm{m}^{2}\right)$ of body fat abnormality in European HIV-infected children and adolescents.

Although many authors have documented an association between PI therapy and deviations in body fat redistribution ${ }^{(5,32,33)}$, the present study did not observe such a relationship. However, metabolic disturbances (dyslipidaemia and insulin resistance) were observed among these patients and described in another publication $^{(12)}$. Jacobson et al. ${ }^{(8)}$ suggested that body fat distribution in HIV-infected children follows a pattern associated with high risk of CVD and possibly related to antiretroviral therapy and disease severity. Other authors have also stated that ever having received PI therapy was not significantly associated with any fat distribution markers among HIV-infected children and adolescents ${ }^{(8,34)}$.

In the current study PI users presented lower mean body fat percentage. The differences seen for stunting prevalence and body fat percentage according to HAART regimens might be correlated and derived from growth deviations. However, it is important to point out that some authors have not considered bioelectrical impedance analysis a good parameter for assessing body fat abnormalities in the paediatric population ${ }^{(7,9)}$

Contri et al. ${ }^{(7)}$ evaluated patients aged 3-17 years under HAART and found that both groups (receiving and not receiving PI therapy) had similar and unchanged body composition. According to these authors, bioelectrical impedance did not predict morphological changes in the children and adolescents evaluated. The authors suggested that other techniques should be applied to better characterize the fat redistribution of HIV-infected patients, including skinfold thickness measurements, segmental bioelectrical impedance technique, dual-energy X-ray absorptiometry and MRI. Despite the fact that bioelectrical impedance analysis has been used to assess body composition in HIVinfected children, it is difficult to analyse the results due to the lack of standards for children. Besides that, bioelectrical impedance analysis measures only whole-body fat and lean body mass, which does not allow the identification of body fat distribution abnormalities ${ }^{(9)}$.

It is important to emphasize that alterations associated with antiretroviral therapy are likely a result of complex interactions between HIV infection, specific antiretroviral agents, age, gender, as well as host genetic and lifestyle factors ${ }^{(30)}$.

The underlying social determinants of malnutrition may contribute to poor nutrition among these patients ${ }^{(27)}$. Common causes for inadequate nutrition are chronic illness, poverty, food insecurity and side-effects of drugs ${ }^{(35)}$. Most of the children and adolescents evaluated in the present study were from low-income backgrounds. Although social support is provided by Brazilian government programmes, they might have been unable to overcome household food insecurity and poverty.

According to Contri et al. ${ }^{(7)}$, long-term investigations with large samples are needed in order to ensure that the weight and height of HIV-infected paediatric patients can be maintained at normal rates. Considering that these parameters are highly correlated ${ }^{(29)}$, HIV-infected children under HAART must be properly monitored in order to avoid deviations in their development and body composition, since other authors have suggested that stunting may have long-term effects on fat distribution ${ }^{(8)}$.

Jacobson et ll $^{\left({ }^{(8)}\right.}$ observed that stunted HIV-infected children had lower percentage of extremity fat and higher percentage of trunk fat. It is well established in the literature that stunted children are more likely to deposit fat centrally later in life ${ }^{(36)}$. Stunted children must adapt to nutritional restriction that affects enzyme and hormone functions, as well as fat oxidation. These children seem to have impaired fat oxidation and are consequently at increased risk of obesity since fat that is not oxidized must be stored ${ }^{(37)}$. It is also well known that specific antiretrovirals and HIV disease severity are found to play a role in the acquisition or loss of body fat ${ }^{(8)}$. Viral load, immune response and the production of inflammatory cytokines seem to adversely affect the growth parameters of HIV-infected patients ${ }^{(7)}$.

Our findings suggest that HAART may be unable to reverse the effects of the disease on the children's linear growth. The present study indicates the importance of monitoring the nutritional status of the paediatric population in routine care appointments so that these disturbances can be detected early and managed appropriately. These 
procedures could reduce the risk of mortality of HIV-infected children and adolescents.

A limitation of the present study is the lack of information regarding the use of antiretrovirals during the whole period of infection since the patients were born. It is also important to point out that this type of study (crosssectional) does not allow for causality assertions.

\section{Conclusions}

The present study documented a high prevalence of stunting in HIV-infected children and adolescents, especially among PI users. The exposure to these antiretrovirals was also associated with lower mean for body fat percentage and lower BMI, which may indicate growth and development deviations. However, we did not see any association between PI exposure and body fat redistribution markers, as stated by many investigators.

\section{Acknowledgements}

Acknowledgements: The authors are grateful to the patients and their parents or caregivers who accepted to participate in the study. They would also like to thank Delanjathan Devakumar for the very useful comments and suggestions to improve the manuscript. Financial support: This research was funded by Fundação de Amparo à Pesquisa do Estado de São Paulo (FAPESP; grant number 2007/50009-3). FAPESP had no role in the design, analysis or writing of this article. Conflict of interest: None. Authorship: L.C.R. designed the study protocol, collected data, participated in the statistical analysis and interpretation of data, and undertook the main writing of the paper; P.H.C.R. secured funding, designed the study protocol, facilitated data collection, and participated in the interpretation of data and writing of the paper; H.H.S.M. assisted in locating the study areas, coordinated data collection, and participated in the interpretation of data and writing of the paper; N.J.S. performed statistical analysis and interpretation of data, and participated in the writing of the paper. All authors read and approved the final manuscript. L.C.R. is guarantor of the paper. Ethics of human subject participation: Informed written consent was obtained from all subjects. The protocol was approved by the Ethical Committees of the School of Public Health and Institute of Child Health/School of Medicine, University of São Paulo, SP, Brazil.

\section{References}

1. Joint United Nations Programme on HIV/AIDS (2013) UNAIDS report on the global AIDS epidemic 2013. http:// www.unaids.org/en/media/unaids/contentassets/documents/ epidemiology/2013/gr2013/UNAIDS_Global_Report_2013_ en.pdf (accessed October 2013).
2. Rudin C, Burri M, Shen Y et al. (2008) Long-term safety and effectiveness of ritonavir, nelfinavir, and lopinavir/ritonavir in antiretroviral-experienced HIV-infected children. Pediatr Infect Dis J 27, 431-437.

3. Peacock-Villada E, Richardson BA \& John-Stewart GC (2011) Post-HAART outcomes in pediatric populations: comparison of resource-limited and developed countries. Pediatrics 127, e423-e441.

4. Ramos NA Jr, Matida LH, Hearst N et al. (2011) AIDS in Brazilian children: history, surveillance, antiretroviral therapy, and epidemiologic transition, 1984-2008. AIDS Patient Care STDS 25, 245-255.

5. Sarni ROS, Souza FIS, Battistini TRB et al. (2009) Lipodystrophy in children and adolescents with acquired immunodeficiency syndrome and its relationship with the antiretroviral therapy. J Pediatr 85, 329-334.

6. Banerjee T, Pensi T, Banerjee D et al. (2010) Impact of HAART on survival, weight gain and resting energy expenditure in HIV-1-infected children in India. Ann Trop Paediatr 30, 27-37.

7. Contri PV, Berchielli EM, Tremeschin MH et al. (2011) Nutritional status and lipid profile of HIV-positive children and adolescents using antiretroviral therapy. Clinics (Sao Paulo) 66, 997-1002.

8. Jacobson DL, Patel K, Siberry GK et al. (2011) Body fat distribution in perinatally HIV-infected and HIV-exposed but uninfected children in the era of highly active antiretroviral therapy: outcomes from the Pediatric HIV/AIDS Cohort Study. Am J Clin Nutr 94, 1485-1495.

9. Tremeschin MH, Sartorelli DS, Cervi MC et al. (2011) Nutritional assessment and lipid profile in HIV-infected children and adolescents treated with highly active antiretroviral therapy. Rev Soc Bras Med Trop 44, 274-281.

10. Sutcliffe CG, Van Dijk JH, Munsanje B et al. (2011) Weight and height Z-scores improve after initiating ART among HIV-infected children in rural Zambia: a cohort study. BMC Infect Dis 11, 54.

11. Matida LH, Ramos AN Jr, Moncau JEC et al. (2007) AIDS by mother-to-child transmission: survival analysis of cases followed from 1983 to 2002 in different regions of Brazil. Cad Saude Piblica 23, S435-S444.

12. Reis LC, Rondó PHC, Marques HHS et al. (2011) Dyslipidaemia and insulin resistance in vertically HIV-infected children and adolescents. Trans R Soc Trop Med Hyg 105, 197-203.

13. World Health Organization (2005) Interim WHO clinical staging of HIV/AIDS and HIV/AIDS case definitions for surveillance. http://www.who.int/hiv/pub/guidelines/clinical staging.pdf (accessed October 2013).

14. Organização Mundial da Saúde (1995) La salud de los jóvenes: un reto y uma esperanza. Geneva: OMS.

15. Tanner JM (1962) Growth at Adolescence, 2nd ed. Oxford: Blackwell Scientific Publications.

16. Frisancho AR (1999) Anthropometric Standards for the Assessment of Growth and Nutritional Status. Ann Arbor, MI: The University of Michigan Press.

17. Lohman TG, Roche AF \& Martorell R (1988) Antbropometric Standardization Reference Manual. Champaign, IL: Human Kinetics Books.

18. World Health Organization (2011) WHO Anthro (version 3.2.2, January 2011) and Macros. Geneva: WHO; available at http://www.who.int/childgrowth/software/en/

19. World Health Organization (2007) Growth reference data for 5-19 years. http://www.who.int/growthref/en/ (accessed October 2013).

20. Frisancho AR (1981) New norms of upper limb fat and muscle areas for assessment of nutritional status. Am J Clin Nutr 34, 2540-2545.

21. McDowell MA, Fryar CD, Hirsch R et al. (2005) Anthropometric reference data for children and adults: US population, 1999-2002. http://origin.cdc.gov/nchs/data/ad/ad361.pdf (accessed October 2013). 
22. Savva SC, Tornaritis M, Savva ME et al. (2000) Waist circumference and waist-to-height ratio are better predictors of cardiovascular disease risk factors in children than body mass index. Int J Obes Relat Metab Disord 24, 1453-1458.

23. Nafiu OO, Burke C, Lee J et al. (2010) Neck circumference as a screening measure for identifying children with high body mass index. Pediatrics 126, e306-e310.

24. Instituto Brasileiro de Geografia e Estatística (2010) Pesquisa de Orçamentos Familiares. Antropometria e Estado Nutricional de Crianças, Adolescentes e Adultos no Brasil. Rio de Janeiro: IBGE; available at http://www.ibge.com.br/home/ estatistica/populacao/condicaodevida/pof/2008_2009_encaa/ pof_20082009_encaa.pdf

25. Arpadi SM (2000) Growth failure in children with HIV infection. J Acquir Immune Defic Syndr 25, S37-S42.

26. Kimani-Murage EW, Norris SA, Pettifor JM et al. (2011) Nutritional status and HIV in rural South African children. BMC Pediatr 11, 23.

27. Chhagan MK, Kauchali S \& Van den Broeck J (2012) Clinical and contextual determinants of anthropometric failure at baseline and longitudinal improvements after starting antiretroviral treatment among South African children. Trop Med Int Health 17, 1092-1099.

28. Chiabi A, Lebela J, Kobela M et al. (2012) The frequency and magnitude of growth failure in a group of HIV-infected children in Cameroon. Pan Afr Med J 11, 15.

29. Buonora S, Nogueira S, Pone MV et al. (2008) Growth parameters in HIV-vertically-infected adolescents on antiretroviral therapy in Rio de Janeiro, Brazil. Ann Trop Paediatr 28, 59-64.
30. Aldrovandi GM, Lindsey JC, Jacobson DL et al. (2009) Morphologic and metabolic abnormalities in vertically HIV-infected children and youth. AIDS 23, 661-672.

31. Alam N, Cortina-Borja M, Goetghebuer T et al. (2012) Body fat abnormality in HIV-infected children and adolescents living in Europe: prevalence and risk factors: fat abnormality in children. I Acquir Immune Defic Syndr 59, 314-324.

32. Bockhorst JL, Ksseiry I, Toye M et al. (2003) Evidence of human immunodeficiency virus-associated lipodystrophy syndrome in children treated with protease inhibitors. Pediatr Infect Dis 22, 463-465.

33. Ramalho LC, Gonçalves EM, Carvalho WR et al. (2011) Abnormalities in body composition and nutritional status in HIV-infected children and adolescents on antiretroviral therapy. Int J STD AIDS 22, 453-456.

34. Arpadi SM, Bethel J, Horlick M et al. (2009) Longitudinal changes in regional fat content in HIV-infected children and adolescents. AIDS 23, 1501-1509.

35. Mothi SN, Karpagam S, Swamy VH et al. (2011) Paediatric HIV: trends \& challenges. Indian J Med Res 134, 912-919.

36. Hoffman DJ, Martins PA, Roberts SB et al. (2007) Body fat distribution in stunted compared with normal-height children from the shantytowns of São Paulo, Brazil. Nutrition 23, 640-646.

37. Hoffman DJ, Sawaya AL, Verreschi I et al. (2000) Why are nutritionally stunted children at increased risk of obesity? Studies of metabolic rate and fat oxidation in shantytown children from São Paulo, Brazil. Am J Clin Nutr 72, 702-707. 